\title{
Gabapentinoids for treatment of neuropathic pain: a medicines usage evaluation at the Groote Schuur Hospital Chronic Pain Management Clinic
}

\author{
MLA Moabelo, R Parker
} Department of Anaesthesia and Perioperative Medicine, University of Cape Town, Cape Town, South Africa
Corresponding author, email:Drew.81@live.com

Background: Neuropathic pain (NP), defined as pain caused by a lesion or disease of the somatosensory system, affects 6.9-10\% of people worldwide. Pregabalin is currently recommended as a first line drug for NP in South Africa.

Methods: A cross-sectional, retrospective, descriptive medicines usage evaluation (MUE) of pregabalin at Groote Schuur Hospital (GSH) Chronic Pain Management Clinic for the year 2017 was conducted. A MUE using a standardised data collection form was performed on 100 randomly selected patient folders. Data was summarised using descriptive statistics.

Results: The majority of cases were women (76) with a mean age of 55.9 years (SD12.49). A diagnosis of NP was recorded in 58 folders and a "possible" diagnosis recorded in 7 folders. In 79 cases there was no mention of a tool/method used to diagnose NP. The most common condition diagnosed was chronic postsurgical pain with a neuropathic component $(n=16)$, followed by NP $(n=15)$. The most common initiating and current dose of pregabalin was $75 \mathrm{mg}$ twice daily. In 56 patients, pregabalin was prescribed in conjunction with a tricyclic antidepressant (TCA) or selective noradrenaline reuptake inhibitor (SNRI). Patient education was documented as having taken place in 76 of cases.

Conclusions: Based on this MUE we recommend the use of screening tools for the diagnosis of neuropathic pain, and a focus on the initiating dose of pregabalin. The use of a standardised assessment document and the interdisciplinary team input at this clinic appears to optimise prescribing of pregabalin in line with practice guidelines.

Keywords: chronic pain clinic, neuropathic pain, pregabalin, prescribing practices

\section{Introduction}

Neuropathic pain is defined as pain caused by a lesion or disease of the somatosensory system. ${ }^{1}$ Neuropathic pain is not a single disease, but a syndrome, which may be caused by a range of different diseases and lesions manifesting as an array of symptoms and signs. Neuropathic pain can further be classified on the basis of etiology; thus, lesions can be central or peripheral, focal or generalised. There are multiple screening tools to aid in the diagnosis of neuropathic pain, including the Leeds Assessment of Neuropathic Symptoms and Signs (LANSS), Douleur Neuropathique 4 (DN4), painDETECT, ID Pain, and neuropathic pain questionnaire. ${ }^{2,3}$

A recent systematic review reported an estimated population prevalence of pain with neuropathic characteristics of between $6.9 \%$ and $10 \% .4,5$

For South Africa, no published prevalence studies of neuropathic pain could be found. However, it is possible that there is a higher prevalence than elsewhere due to the burden of HIV/AIDS and diabetes, both of which are often associated with painful peripheral neuropathies. The prevalence of neuropathic pain was reported as $23 \%$ among South African AIDS patients who had not received prior antiretroviral treatment, increasing to $40 \%$ in HIV-positive black South Africans exposed to stavudine. ${ }^{6}$ Stavudine, a nucleoside reverse transcriptase antiretroviral is neurotoxic, causing peripheral neuropathy in a dose dependent manner. The wide spectrum of diseases with a neuropathic component, combined with the different tools used to diagnose neuropathic pain, makes evaluation of epidemiological studies difficult.

The pathology of neuropathic pain is complex and it is therefore not surprising that all treatment guidelines recommend multimodal treatment strategies and a biopsychosocial approach. ${ }^{7}$ To select the most effective multimodal approach, the pathological mechanisms that contribute to neuropathic pain need to be considered to inform the selection of treatments that target those mechanisms.

The consequences of lesions in the somatosensory system include peripheral and central sensitization. ${ }^{8}$ Lesions in the peripheral nerves result in peripheral sensitization via an increased expression of $\mathrm{Na}^{+}$channels and voltage gated $\mathrm{Ca}^{2+}$ channels in the $\mathrm{C}$ - and $\mathrm{A} \delta$-nociceptive fibres. This sensitization results in spontaneous ectopic-like discharges, decreased threshold of activation, and enhanced responsiveness to stimuli. ${ }^{8}$ Input from sensitised C-fibres can initiate and maintain activity-dependant central sensitization in the dorsal horn of the spinal cord with enhanced neural excitability due to enhanced neurotransmitter release (glutamate) and upregulation of glutamate (N-Methyl D-Aspartate) NMDA receptors. ${ }^{9}$ The enhanced excitability and upregulation results in expansion of the receptive field and abnormal neural sprouting within the dorsal horn of the spinal cord. ${ }^{8,9}$ All these changes alter nociceptive transmission manifesting clinically as hyperalgesia and allodynia.

Another mechanism that contributes to central sensitization is the dysfunction of the descending inhibitory serotonergic and noradrenergic pathways. Originating from the anterior cingulate 
gyrus, amygdala and hypothalamus, and traveling via the brain stem nuclei in the periaqueductal grey and rostroventral medial medulla, the descending inhibitory pathways modulate the spinal transmission of nociceptive input at the spinal cord. ${ }^{9}$ The neurotransmitters involved include noradrenaline, serotonin, and endogenous opioids. After a nerve injury, these pathways begin to dysfunction resulting in the effect of noradrenaline on $a_{2}$ noradrenergic receptors being suspended, with a net effect of the serotonergic input changing from inhibition to facilitation. ${ }^{10}$ Therefore, the use of tricyclic antidepressants and serotonin noradrenaline reuptake inhibitors (SNRI) in the treatment of NP aims to facilitate endogenous inhibition and inhibit central sensitization.

As is evident from the above discussion of neuropathic mechanisms, the $\mathrm{Ca}^{2+}$ channels in the spinal cord are potential targets for the treatment of neuropathic pain. $\mathrm{Ca}^{2+}$ is required for exocytosis of vesicles containing neurotransmitters from the presynaptic neuron into the synapse. By blocking or decreasing activity of the $\mathrm{Ca}^{2+}$ channels, a reduction in the synaptic release of excitatory neurotransmitters such as glutamate, substance $P$, noradrenaline, serotonin and calcitonin gene-related peptide results. By reducing the release of excitatory neurotransmitters, the effect of peripheral sensitization can be reduced, and central sensitization mechanisms diminished. The gabapentinoids, derivatives of the inhibitory neurotransmitter g-aminobutyric acid (GABA), bind to the $a_{2} \delta$ auxiliary subunit of voltagegated calcium channels, decreasing the influx of $\mathrm{Ca}^{2+}$ into the presynaptic neuron. ${ }^{11}$

The gabapentinoids include pregabalin and gabapentin. Pregabalin is more potent and has a higher binding affinity for the $a_{2} \delta$ subunit of voltage gated calcium channels than gabapentin. ${ }^{11}$ In South Africa, pregabalin is currently recommended as a first line drug for treatment of neuropathic pain. ${ }^{12}$ Pregabalin is hydrophilic and double stranded at neutral $\mathrm{pH}$, and so it crosses membrane barriers via a specialised transport system (system L). ${ }^{11,13}$ Pregabalin has an oral bioavailability of up to $90 \%$ and time to peak plasma concentration in healthy volunteers is one hour. Absorption of pregabalin is not saturable, resulting in a linear pharmacokinetic profile. It undergoes less than $1 \%$ metabolism and $95 \%$ is excreted unchanged by the kidneys. As pregabalin clearance decreases with increasing age and decreased creatine clearance, dose reduction is recommended in elderly patients ( $>65$ years) and patients with compromised renal function.

Pregabalin has been used at the GSH Chronic Pain Management Clinic (CPMC) for eight years. The license on the drug has recently expired, and, with a potential shift in availability, it is appropriate to conduct a Medicines Usage Evaluation (MUE) to optimise future practice. GSH Chronic Pain Management Clinic is a specialist run clinic, treating an average of 100 patients monthly. On average, patients seen at the clinic are 52.8 years; predominantly female (68.7\%) and unemployed (51\%). We conducted a MUE of pregabalin in the chronic pain management clinic of Groote Schuur Hospital to describe the prescription pattern and clinical use.

\section{Methods}

A cross-sectional retrospective descriptive chart review of the use of pregabalin in Groote Schuur Hospital Chronic Pain Management Clinic for the year 2017 was conducted. This type of study design allows the researchers to investigate the characteristics of this specific population at one point in time and helps to identify the indications for pregabalin prescription.

To obtain a representative sample of prescribing practices in this population, the WHO recommends sampling a population of 100 patients. ${ }^{14}$ As this study aimed to describe prescribing practice of clinicians in the Groote Schuur Hospital Chronic Pain

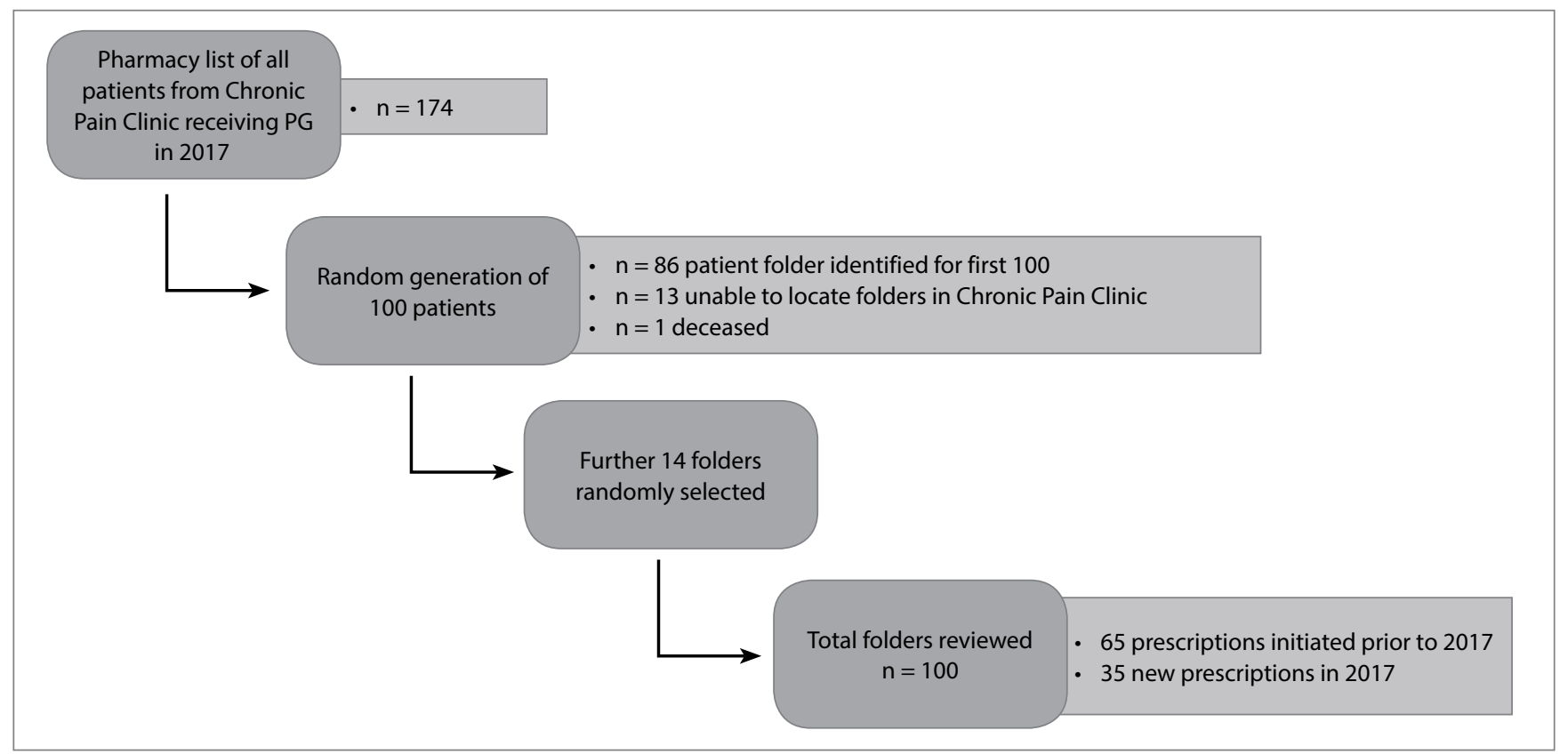

Figure 1: Flow chart illustrating data collection process 
Management Clinic, the population was patients being treated with pregabalin at the CPMC of GSH in one year.

From a list of 174 patients receiving pregabalin in 2017, 100 folders were retrieved. (Figure 1). A medicine use evaluation (MUE) chart for pregabalin based on the literature was developed (Appendix A). Each question in the data collection chart was peer reviewed by a chronic pain specialist. Items on the data collection sheet included: a documented diagnosis of neuropathic pain, the diagnostic tool used for the diagnosis, and documentation of the severity and duration of the condition. Charts were also examined to determine the presence of patient associated factors including age, gender, and presence of comorbidities, allergies, pregnancy and breastfeeding. Data were collected on the prescribing practice of the clinician with respect to documentation of dosage, interval and duration of pregabalin, consideration of other medications used by the patient and the possible interactions. Data from the MUE were entered into an Excel spreadsheet. Descriptive statistics were used to summarise the data that are presented as mean (SD) or frequencies.

\section{Results}

The mean patient age was 55.9 years (SD12.49), ranging from 27-88 years, and the majority (76 out of 100 ) were women (Table I). In all of the 100 folders reviewed, patient details including age, gender, presence of co-morbidities and allergies were documented. In one folder, note was made that screening for pregnancy was performed. In terms of socioeconomic profile, all 100 folders had documentation of whether the patient was receiving some form of social grant (disability grant or pension) with 36 documented as receiving a grant (Table I).

Table I: Demographic characteristics $(n=100)$

\begin{tabular}{lc}
\hline Descriptor & Mean (SD) \\
\hline Age & $55.9(12.49)$ \\
\hline Gender & Frequency (\%) \\
\hline Female & 76 \\
\hline Male & 24 \\
Receiving a social grant & 36 \\
\hline Applying for a disability grant & 6 \\
\hline Temporary disability grant & 7 \\
\hline Permanent disability grant & 22 \\
\hline Workmen's compensation application & 1 \\
\hline
\end{tabular}

\section{Diagnosis of neuropathic pain}

The first criteria explored in the MUE was whether a diagnosis of NP was documented and whether a diagnostic tool was used to assist in making the diagnosis. A "diagnosis of NP" was classified as being made if the notes specified neuropathic pain, neuropathy, radiculopathy, complex regional pain syndrome (CRPS) or post-herpetic neuralgia. A "possible diagnosis of NP" was classified as being made if the terms "possible" or "query" were used in the documentation in conjunction with any of the above terms. If no documentation was found using the above terms, a diagnosis of NP was recorded as not being documented. A clear diagnosis of NP was documented in 58 of the folders with a "possible" diagnosis recorded in a further seven folders (Table II).

Table II: Recording of neuropathic pain diagnosis and method used $(n=100)$

\begin{tabular}{lc}
\hline Diagnosis of Neuropathic Pain Recorded & Frequency (\%) \\
\hline Yes & 58 \\
\hline Possible diagnosis & 7 \\
\hline No & 35 \\
\hline Diagnostic tool/method recorded & \\
\hline None recorded & 79 \\
\hline Yes (EMG method recorded) & 2 \\
\hline Yes (used a diagnostic tool) & 19 \\
\hline
\end{tabular}

The DN4 was used as a diagnostic tool for NP in one of the folders reviewed. The Budapest Criteria for the diagnosis of CRPS were completed in 18 folders. The criteria confirmed the diagnosis of CRPS in 9 cases (four CRPS Type 1; five CRPS Type II), with nine cases not meeting the criteria for CRPS. In two folders, EMG studies were documented as being performed, one of these was normal and one confirmed a diagnosis of NP.

The most common diagnoses were the neuropathic pain syndromes, which were recorded in 35 of the folders (Table III). The most common single condition diagnosed was chronic post-surgical pain with a neuropathic component $(n=16)$. This was followed by a diagnosis of neuropathic pain $(n=15)$ and radiculopathy $(n=12)$.

\section{Documentation of condition (pain severity, duration)}

Pain severity was documented in 96 of the folders reviewed. The Brief Pain Inventory ${ }^{15}$ was used to record pain severity and pain interference with function in 87 of the folders. Other methods used to record pain severity were the verbal rating scale (mild/ moderate/severe) $(n=8)$, and the visual analogue scale $(n=1)$. The length of time the symptoms had been present was documented in all 100 folders with either the date of injury or surgery recorded or the number of months/years since the onset of pain.

\section{Documentation of medical management}

In 99 of the folders, there was clear documentation regarding medication other than pregabalin being prescribed. In 11 of these folders, potential interactions with pregabalin were noted.

In terms of pregabalin dosages, clear prescribing was documented in all 100 folders including dosage, interval and duration. The most common initiating dose was $75 \mathrm{mg}$ twice daily (Table IV). There was a wide variety of current doses recorded with the most common being $75 \mathrm{mg}$ twice daily (Table V). One patient had stopped using the drug. 
Table III: Diagnoses recorded in the patient folders

\begin{tabular}{|c|c|}
\hline Diagnosis & Frequency (\%) \\
\hline Neuropathic diagnoses & 35 \\
\hline Neuropathic pain & 15 \\
\hline Complex regional pain syndrome Type 2 & 5 \\
\hline Complex regional pain syndrome Type I & 4 \\
\hline Trigeminal neuralgia & 3 \\
\hline Post herpetic neuralgia & 3 \\
\hline Phantom limb pain & 2 \\
\hline Peripheral neuropathy & 1 \\
\hline Retroviral disease peripheral neuropathy & 1 \\
\hline Motor axonal neuropathy & 1 \\
\hline Spinal pain & 26 \\
\hline Radiculopathy & 12 \\
\hline Spinal stenosis & 7 \\
\hline Chronic lower back pain & 4 \\
\hline Tuberculosis of the spine & 1 \\
\hline Spondylosis & 1 \\
\hline Chronic lower back pain with neuropathic pain & 1 \\
\hline Chronic post-surgical pain & 25 \\
\hline $\begin{array}{l}\text { Chronic post-surgical pain with a neuropathic } \\
\text { component }\end{array}$ & 16 \\
\hline Failed back syndrome & 5 \\
\hline Chronic post-surgical pain & 2 \\
\hline Failed back syndrome with fibromyalgia & 1 \\
\hline Chronic post-surgical pain \& fibromyalgia & 1 \\
\hline Other & 14 \\
\hline Fibromyalgia & 7 \\
\hline Chronic pelvic pain & 3 \\
\hline Chronic epigastric pain & 1 \\
\hline Carpal tunnel syndrome \& fibromyalgia & 1 \\
\hline Loin pain haematuria & 1 \\
\hline Chronic pancreatitis & 1 \\
\hline
\end{tabular}

Table IV: Frequency of initiating doses of pregabalin $(n=100)$

\begin{tabular}{lc}
\hline Initiating Dose & Frequency (\%) \\
\hline Night only & 14 \\
\hline $25 \mathrm{mg}$ & 2 \\
\hline $50 \mathrm{mg}$ & 15 \\
\hline $75 \mathrm{mg}$ & 31 \\
\hline Total night only & \\
\hline Twice daily & 19 \\
\hline $25 \mathrm{mg}$ & 2 \\
\hline $25 \mathrm{mg}$ morning/50 mg night & 19 \\
\hline $25 \mathrm{mg}$ morning/75 mg night & 20 \\
\hline $75 \mathrm{mg}$ & 1 \\
\hline $100 \mathrm{mg}$ & 5 \\
\hline $150 \mathrm{mg}$ & 3 \\
\hline $300 \mathrm{mg}$ & 69 \\
\hline Total twice daily & \\
\hline
\end{tabular}

Table V: Frequency of current doses of pregabalin $(n=100)$

\begin{tabular}{|c|c|}
\hline Current dose & Frequency (\%) \\
\hline \multicolumn{2}{|l|}{ Night only } \\
\hline $25 \mathrm{mg}$ & 5 \\
\hline $50 \mathrm{mg}$ & 4 \\
\hline $75 \mathrm{mg}$ & 14 \\
\hline $150 \mathrm{mg}$ & 1 \\
\hline \multicolumn{2}{|l|}{ Twice daily } \\
\hline \multicolumn{2}{|l|}{ Uneven dosing } \\
\hline $25 \mathrm{mg}$ morning/75 mg night & 9 \\
\hline 50 mg morning/75 mg night & 2 \\
\hline $50 \mathrm{mg}$ morning/100 mg night & 1 \\
\hline $25 \mathrm{mg}$ morning/150 mg night & 1 \\
\hline 50 mg morning 150 mg night & 1 \\
\hline 75 mg morning/150 mg night & 7 \\
\hline 100 mg morning/150 mg night & 2 \\
\hline 75 mg morning/225 mg night & 1 \\
\hline 150 mg morning/225 mg night & 2 \\
\hline 150 mg morning/300 mg night & 1 \\
\hline 150 mg morning/300 mg night & 2 \\
\hline 275 mg morning/300 mg night & 1 \\
\hline \multicolumn{2}{|l|}{ Even dosing } \\
\hline $25 \mathrm{mg}$ & 1 \\
\hline $75 \mathrm{mg}$ & 21 \\
\hline $150 \mathrm{mg}$ & 17 \\
\hline $225 \mathrm{mg}$ & 2 \\
\hline $300 \mathrm{mg}$ & 4 \\
\hline Stopped & 1 \\
\hline
\end{tabular}

Patients were receiving a wide variety of other medications indicated for pain including analgesics and centrally acting drugs (Table VI). The majority (95 patients) were receiving analgesics in addition to pregabalin. Only five patients were receiving no medication other than pregabalin.

There were 56 cases where pregabalin was prescribed in conjunction with an antidepressant (TCA or SNRI). Notably, in seven folders, patients were prescribed pregabalin with both a TCA and a SNRI. More than half of the patients were on weak opioids, (tramadol, $\mathrm{n}=50$ ) with a further 14 on morphine.

A follow-up plan in terms of a reassessment date to evaluate the effect of the treatment was documented in all 100 folders. In 96 of the folders, patients were documented as being referred for non-pharmacological treatment (physiotherapy or psychology).

\section{Patient education}

Patient education was documented as having taken place in 76 of the folders. The education conducted varied in topic. In 28 folders it was recorded that patients were educated about pregabalin, its effects and potential side effects. In 30 folders it was recorded that patients received pain neuroscience education. In 48 folders it was recorded that patients were referred to the Physiotherapy led Chronic Pain Management Program which includes education on both pharmacological and non-pharmacological 
Table VI: Other medications documented for pain management $(n=100)$

\begin{tabular}{|c|c|c|c|c|c|c|c|}
\hline $\begin{array}{l}\text { Medication: } \\
\text { Analgesics }\end{array}$ & $\begin{array}{c}\text { Frequency } \\
\text { (\%) }\end{array}$ & $\begin{array}{l}\text { Medication: TCA/ } \\
\text { SSRI/SNRI }\end{array}$ & $\begin{array}{c}\text { Frequency } \\
\text { (\%) }\end{array}$ & $\begin{array}{l}\text { Medication: } \\
\text { Central acting }\end{array}$ & $\begin{array}{c}\text { Frequency } \\
\text { (\%) }\end{array}$ & $\begin{array}{l}\text { Medication: } \\
\text { Other }\end{array}$ & $\begin{array}{c}\text { Frequency } \\
(\%)\end{array}$ \\
\hline Paracetamol & & $\begin{array}{l}\text { Amitriptyline } \\
\text { (nocte) }\end{array}$ & 37 & Carbamazepine & 7 & \multicolumn{2}{|c|}{ Prednisone } \\
\hline $1 \mathrm{~g}$ QID & 78 & $10 \mathrm{mg}$ & 7 & $100 \mathrm{mg}$ & 4 & $7.5 \mathrm{mg}$ & 1 \\
\hline \multirow[t]{2}{*}{$1 \mathrm{gTDS}$} & 6 & $25 \mathrm{mg}$ & 12 & $200 \mathrm{mg}$ & 3 & $60 \mathrm{mg}$ & 1 \\
\hline & & $50 \mathrm{mg}$ & 10 & & & & \\
\hline Tramadol & & $75 \mathrm{mg}$ & 5 & $\begin{array}{l}\text { Clonidine } \\
\text { (25-150 mcg) }\end{array}$ & 8 & & \\
\hline 100 mg QID & 36 & $100 \mathrm{mg}$ & 2 & & & & \\
\hline $50 \mathrm{mg}$ TDS & 10 & $200 \mathrm{mg}$ & 1 & Baclofen & & & \\
\hline $100 \mathrm{mg}$ TDS & 2 & & & $10 \mathrm{mg}$ TDS & 1 & & \\
\hline $50 \mathrm{mg} \mathrm{BD}$ & 1 & Venlafaxine & 19 & $20 \mathrm{mg}$ TDS & 1 & & \\
\hline \multirow[t]{2}{*}{$25 \mathrm{mg}$} & 1 & $150 \mathrm{mg}$ & 3 & & & & \\
\hline & & $175 \mathrm{mg}$ & 11 & & & & \\
\hline Morphine & & $225 \mathrm{mg}$ & 4 & & & & \\
\hline 10 mg QID & 6 & $300 \mathrm{mg}$ & 1 & & & & \\
\hline \multirow[t]{4}{*}{20 mg QID } & 8 & & & & & & \\
\hline & & Mianserin $30 \mathrm{mg}$ & 2 & & & & \\
\hline & & Fluoxetine $20 \mathrm{mg}$ & 1 & & & & \\
\hline & & Citalopram $20 \mathrm{mg}$ & 1 & & & & \\
\hline
\end{tabular}

management of pain, pain neuroscience education, selfmanagement training, exercise and relaxation training. Seven of the 48 referred to this program were documented as not having attended.

\section{Discussion}

A cross-sectional retrospective MUE of the use of pregabalin at Groote Schuur Hospital Chronic Pain Management Clinic in 2017 was conducted. The mean age of the patients reviewed was 55.9 years (SD12.49); a large proportion were females $(n=76)$ and more than a quarter $(n=36)$ were receiving or applying for social grants. Although it is possible that our population was biased, as Groote Schuur Hospital is an academic tertiary hospital that predominantly services those who do not have access to private health insurance or private healthcare, this profile is similar to that reported in the literature on chronic neuropathic pain with the condition being more prevalent in older individuals, females, and in those of low socioeconomic status. ${ }^{5}$

A comparison of our patient population with medicines usage evaluations in countries as varied as the United Kingdom, Sweden and Japan, shows a similar pattern with regard to age and gender distribution. The UK cohort, had a median age of 59 years and the majority were female $(60.1 \%),{ }^{16}$ while in Sweden the median age was 55 years, of which $63 \%$ were female. ${ }^{17}$ The Japanese cohort was slightly older (66.8 years) with $51 \%$ females. ${ }^{18}$

In this study, the most common condition diagnosed was chronic post-surgical pain with a neuropathic component $(n=16)$. Posttraumatic and post-surgical nerve injuries are common causes of NP with post-herpetic neuralgia and distal polyneuropathy the next most common causes. ${ }^{19,20}$ In a tertiary care hospital in Saudi Arabia, the majority of patients were receiving pregabalin for painful diabetic neuropathy ${ }^{21}$ whereas a UK primary care setting reported that only $17.8 \%$ of the pregabalin prescriptions were for neuropathic pain with the majority being for epilepsy. ${ }^{16}$ The GSH cohort appeared to be different, with spinal related neuropathic pain being more common than the post-herpetic neuralgias and distal polyneuropathies reported as the most common conditions in other settings. This might be due to the presence of a specialist diabetic clinic at the hospital where patients with diabetic related distal polyneuropathy may be managed without referral to the pain clinic. Alternatively, these patients may be receiving treatment at a primary health care level. It is likely that these patients are being treated elsewhere as the incidence of both painful diabetic neuropathy and post-herpetic neuralgia in South Africa are reported to be higher than elsewhere in the world as a consequence of the prevalence of diabetes and HIV. ${ }^{6,22,23}$

According to the South African guidelines, pregabalin is indicated for use in the presence of neuropathic pain only, specifically for post-herpetic neuralgia and painful diabetic neuropathy. . $2,24,25^{2}$ It is encouraging that in the majority of folders reviewed, pregabalin was being prescribed according to evidence-based guidelines unlike the $35.5 \%$ diagnostic rate of neuropathic pain reported in a Swedish setting. ${ }^{17}$ However, this diagnostic rate still falls short of expectations.

The diagnosis of NP is made on history and clinical examination, which can be facilitated by a variety of screening tools. There are five validated screening tools recommended for use in the diagnosis of neuropathic pain: the DN4, LANSS, painDETECT, ID 
Pain and neuropathic pain questionnaire. ${ }^{3}$ Most of these tools have a sensitivity and specificity of about $80 \%^{3}$ indicating that the screening tools fail to clearly identify neuropathic pain in $20 \%$ of cases. In an ideal practice setting, a MUE of pregabalin where screening tools are routinely used would report $80 \%$ of the patients as having a clear diagnosis of neuropathic pain and the remainder being diagnosed with "possible" neuropathic pain. In this study, a neuropathic pain screening tool was only used in 21 cases. The routine use of neuropathic screening tools may optimise the diagnosis and management of neuropathic pain.

Current guidelines recommend initiating pregabalin at a dosage of $25 \mathrm{mg}$ at night to minimise initial side effects; with a maximum dose of $300-400 \mathrm{mg}$ daily in divided doses, to minimise dose dependent side effects. ${ }^{7,12,26}$ The South African Medicines Formulary (SAMF), MIMS and the pregabalin package insert recommend different initiating doses from those in the guidelines. ${ }^{24,25}$ In the SAMF and MIMS this is $75 \mathrm{mg}$ twice daily, while $150 \mathrm{mg}$ in two or three divided doses is specified in the package insert. This difference in recommendations, might contribute to variations in the prescribed initiating dose for pregabalin. Several factors have been identified which directly and indirectly affect prescribing patterns. ${ }^{27}$ These include the clinical and behavioural characteristics of the patient, scientific evidence, drug efficacy, habitual or non-habitual choice, peer influence (community of physicians), education and pharmaceutical advertising, and the high cost of drugs. The patients seen at chronic pain clinic are usually patients that have experienced incomplete or failed management from another hospital or specialist clinic, and so they often present with complex pathology and anxiety. Pregabalin's high symptom amelioration and effectiveness makes it a common first line drug for the treatment of neuropathic pain. Peer influence may play a role as the clinic is staffed by one consultant with registrars rotating every two months. It is likely that the consultant influences the registrar prescribing pattern more than the current literature as a consequence of the conflicting recommendations. ${ }^{12,24}$ However, to make a definitive statement regarding the influence of these factors on prescriber practice, a study of clinical reasoning processes is needed.

The efficacy of simple analgesics for neuropathic pain has not been established. However, 84 patients were on paracetamol, a simple analgesic agent. As mentioned above, physician prescribing practice is influenced by multiple factors. The high usage of paracetamol might be due to the concomitant presence of complex pain with a nociceptive component (the clinical characteristics of the patient) or to prescribing practices related to habit and peer influence. ${ }^{27}$ In addition, 56 patients were on combination treatment with an SNRI or TCA. These antidepressants are recommended for the management of neuropathic pain as first line (monotherapy) or second line (combination) therapy with pregabalin. ${ }^{7,12,26}$ The concomitant use of these drugs in neuropathic pain target the mechanisms of dysfunction in the descending inhibitory pathway and address the mood and sleep disorders associated with chronic pain states. As mentioned in the introduction, the neurotransmitters involved in this pathway include serotonin and noradrenaline. The use of these drugs in addition to pregabalin potentiates the descending inhibitory pathways and thus inhibits central sensitization.

In all 100 folders reviewed, documentation of medical conditions, allergies, and medication doses were correctly recorded. In addition, pain severity was fully documented using the Brief Pain Inventory (BPI) in 96 of the folders reviewed. There was a $100 \%$ follow up of patients, where treatment effectiveness and development of side effects was reviewed. The excellent documentation and follow-up is most likely achieved due to the use of a standardised assessment document used in the initial assessment of the patient. This standardised assessment document incorporates the BPI in addition to sections for past medical history (including history of mental health disorders), social history, level of education and employment, current mood and evaluation of the patient's ideas, concerns and expectations. Therefore, this document thoroughly covers a biopsychosocial patient history and allows for the documentation of the management plan by the interdisciplinary team. The use of this document means every patient assessment is standardised, reminds clinicians of important factors to document, and reduces the risk of clinician bias or fatigue, habitual choices and peer influence, and facilitates patient follow-up. ${ }^{28}$

All current guidelines on the management of neuropathic pain and any chronic pain state emphasise the importance of a multidisciplinary team approach to the treatment of neuropathic pain, as well as the role of patient education. 12,20,29 In this MUE, 96 patients were referred for non-pharmacological management of pain, documented as referral for physiotherapy, psychiatry, psychology, mirror therapy, graded motor imagery therapy, breathing and relaxation techniques. Patient education was specifically recorded in 76 of the folders, including education about pregabalin, its effects and side effects, pain neuroscience and the chronic pain management program. Documentation included decisions made at regular interdisciplinary meetings (medical doctors, physiotherapists, psychologists, consultation liaison psychiatrists) where each new patient is discussed, and appropriate management plans developed according to guidelines recommending holistic, pharmacological and nonpharmacological approaches for better efficacy. ${ }^{20}$

This study was a retrospective descriptive chart review of one hundred randomly selected folders reducing selection bias. Misclassification bias was minimised by the investigators performing all the data collection. The 100 folders represent $57.47 \%$ of the prescriptions written for pregabalin by the chronic pain clinic in one year, limiting generalizability. Our study was conducted in an academic, public hospital where the patient population may be of lower socioeconomic status and have a higher burden of co-morbidities than elsewhere. 


\section{Conclusion}

Based on this study we recommend the routine use of screening tools in the diagnosis of neuropathic pain, in particular the use of the DN4 screening tool as per the South African guidelines. ${ }^{12}$ We also recommend initiating pregabalin at a dose of $25 \mathrm{mg}$ at night and titrating subsequent doses over one to two weeks based on efficacy and side effects to a maximum of $400 \mathrm{mg}$ daily in divided doses. Finally, we recommend that the risks of polypharmacy be raised with prescribers with emphasis on ceasing drugs that are not effective for the treatment of any given condition. The use of pregabalin in this Chronic Pain Management Clinic is characterised by appropriate prescribing for neuropathic pain, good clinical documentation and appropriate management with follow-up. This clinical practice may have been facilitated by the use of a standardised assessment document, the involvement of an interdisciplinary team with every new patient and active engagement with patients regarding treatment options. It would be beneficial to specifically explore the effects of these practices on patient care.

\section{Ethics approval}

Ethical approval was obtained from the Faculty of Health Sciences Human Research Ethics Committee (Ref: 278/2018), Groote Schuur Hospital Department of Health (DoH) Ethics Committee and the Groote Schuur Hospital pharmacy manager.

\section{References}

1. Jensen TS, Baron R, Haanpaa M, Kalso E, Loeser JD, Rice AS, et al. A new definition of neuropathic pain. Pain. 2011;152(10):2204-5.

2. Bennett M. The LANSS Pain Scale: the Leeds assessment of neuropathic symptoms and signs. Pain. 2001;92(1-2):147-57.

3. Mulvey MR, Bennett MI, Liwowsky I, Freynhagen R. The role of screening tools in diagnosing neuropathic pain. Pain Manag. 2014;4(3):233-43.

4. van Hecke O, Austin SK, Khan RA, Smith BH, Torrance N. Neuropathic pain in the general population: a systematic review of epidemiological studies. Pain. 2014;155(4):654-62.

5. Posso IdP, Palmeira CCdA, Vieira ÉBdM. Epidemiology of neuropathic pain. Revista Dor. 2016;17:11-4.

6. Maritz J, Benatar M, Dave JA, Harrison TB, Badri M, Levitt NS, et al. HIV neuropathy in South Africans: frequency, characteristics, and risk factors. Muscle Nerve. 2010;41(5):599-606.

7. Dworkin RH, O'Connor AB, Kent J, Mackey SC, Raja SN, Stacey BR, et al. Interventional management of neuropathic pain: NeuPSIG recommendations. Pain. 2013;154(11):2249-61.

8. Woolf $\mathrm{CJ}$. Central sensitization: implications for the diagnosis and treatment of pain. Pain. 2011;152(3 Suppl):S2-15.

9. Costigan $M$, Scholz J, Woolf CJ. Neuropathic pain: a maladaptive response of the nervous system to damage. Annu Rev Neurosci. 2009;32:1-32.
10. Bee LA, Dickenson AH. Descending facilitation from the brainstem determines behavioural and neuronal hypersensitivity following nerve injury and efficacy of pregabalin. Pain. 2008;140(1):209-23.

11. Bockbrader HN, Wesche D, Miller R, Chapel S, Janiczek N, Burger P. A comparison of the pharmacokinetics and pharmacodynamics of pregabalin and gabapentin. Clini pharmacokinet. 2010;49(10):661-9.

12. Chetty S, Baalbergen E, Bhigjee Al, Kamerman P, Ouma J, Raath $R$, et al. Clinical practice guidelines for management of neuropathic pain: expert panel recommendations for South Africa. S Afr Med J. 2012;102(5):312-25.

13. Sills GJ. The mechanisms of action of gabapentin and pregabalin. Curr Opin Pharmacol. 2006;6(1):108-13.

14. Organization WH. Promoting rational use of medicines: core component. 2002-3 ed2002.

15. Cleeland CS, Ryan KM. Pain assessment: global use of the Brief Pain Inventory. Ann Acad Med Singapore. 1994;23(2):129-38.

16. Asomaning K, Abramsky S, Liu Q, Zhou X, Sobel RE, Watt S. Pregabalin prescriptions in the United Kingdom: a drug utilisation study of The Health Improvement Network (THIN) primary care database. Int J Clin Pract. 2016;70(5):380-8.

17. Wettermark $B$, Brandt $L$, Kieler $H$, Boden R. Pregabalin is increasingly prescribed for neuropathic pain, generalised anxiety disorder and epilepsy but many patients discontinue treatment. Int J Clin Pract. 2014;68(1):104-10.

18. Hirakata M, Yoshida S, Tanaka-Mizuno S, Kuwauchi A, Kawakami K. Pregabalin Prescription for Neuropathic Pain and Fibromyalgia: A Descriptive Study Using Administrative Database in Japan. Pain Res Manag. 2018;2018:2786151.

19. DiBonaventura MD, Sadosky A, Concialdi K, Hopps M, Kudel I, Parsons B, et al. The prevalence of probable neuropathic pain in the US: results from a multimodal general-population health survey. J Pain Res. 2017;10:2525-38.

20. Centre for Clinical Practice at N. National Institute for Health and Care Excellence: Clinical Guidelines. Neuropathic Pain: The Pharmacological Management of Neuropathic Pain in Adults in Non-specialist Settings. London: National Institute for Health and Care Excellence, (UK) National Institute for Health and Care Excellence; 2013.

21. Maha E Aljuhanei aMA. Pregabalin Medication Use Evaluation in a Tertiary Care Hospital in Riyadh. Global Pharmaceutical and Medical Research Conference (GPMRC) 2017; 14th - 15th April 2017; Sheraton Dubai Creek, UAE2017.

22. Jacovides A, Bogoshi M, Distiller LA, Mahgoub EY, Omar MK, Tarek IA, et al. An epidemiological study to assess the prevalence of diabetic peripheral neuropathic pain among adults with diabetes attending private and institutional outpatient clinics in South Africa. J Int Med Res. 2014;42(4):1018-28.

23. Shearer K, Maskew M, Ajayi T, Berhanu R, Majuba P, Sanne I, et al. Incidence and predictors of herpes zoster among antiretroviral therapy-naive patients initiating HIV treatment in Johannesburg, South Africa. Int J Infect Dis. 2014;23:56-62.

24. South African medicines formulary. 12 ed. Rondebosch, South Africa: Health and Medical Pub. Group of the South African Medical Association; 2016.

25. Monthly Index of Medical specialities. Cape Town, 2018 Nov.

26. Attal N, Cruccu G, Baron R, Haanpaa M, Hansson P, Jensen TS, et al. EFNS guidelines on the pharmacological treatment of neuropathic pain: 2010 revision. Eur J Neurol. 2010;17(9):1113-e88.

27. Murshid MA, Mohaidin Z. Models and theories of prescribing decisions: A review and suggested a new model. Pharm Pract. 2017;15(2):990.

28. O'Sullivan ED, Schofield SJ. Cognitive bias in clinical medicine. J R Coll Physicians Edinb. 2018;48(3):225-32.

29. Scascighini L, Toma V, Dober-Spielmann S, Sprott H. Multidisciplinary treatment for chronic pain: a systematic review of interventions and outcomes. Rheumatology (Oxford, England). 2008;47(5):670-8.

30. University of Cape Town, Knowledge Translation Unit. The Practical Approach to Care Kit (PACK); Global Adult [Internet]. Cape Town: KTU; 2017 [cited 201728 September 2017]. Available from: http://pack.bmj.com/ pack-global-adult-2017-ebook-v1

31. Finch $\mathrm{E}$, Geddes EL, Larin H. Ethically-based clinical decision-making in physical therapy: process and issues. Physiother Theory Pract. 2005;21(3):147-62. 
Appendix A: MUE

\begin{tabular}{|c|c|c|c|}
\hline Criteria & & DATA RECORDED & REFERENCES \\
\hline Diagnosis: neuropathic pain & $\begin{array}{l}\text { Has the clinician documented neuropathic pain as the } \\
\text { diagnosis? }\end{array}$ & $\mathrm{Y} / \mathrm{N}$ & Chetty S, et al. 2012 \\
\hline Diagnostic tool & $\begin{array}{l}\text { Was a diagnostic tool such as the DN4/LANSS or } \\
\text { Budapest criteria used? }\end{array}$ & $\begin{array}{c}\mathrm{Y} / \mathrm{N} \\
\text { Document data }\end{array}$ & Chetty S, et al. 2012 \\
\hline Severity & $\begin{array}{l}\text { Has the clinician documented severity of the pain? } \\
\text { Either mild/moderate/severe or NRS (out of 10) }\end{array}$ & $\begin{array}{c}\mathrm{Y} / \mathrm{N} \\
\text { Document data }\end{array}$ & \\
\hline Duration & $\begin{array}{l}\text { Has the duration of the pain been documented? Days } \\
\text { or months }\end{array}$ & $\begin{array}{c}\mathrm{Y} / \mathrm{N} \\
\text { Document data }\end{array}$ & \\
\hline Patient details & $\begin{array}{l}\text { Patient age, gender, any current co-morbidities, } \\
\text { pregnant, breastfeeding, allergies been documented? }\end{array}$ & Document data & $\begin{array}{l}\text { Practical Approach to Care } \\
\text { Kit (PACK); Global Adult } \\
2017 .^{30} \\
\text { Finch E, Geddes EL, Larin } \\
\text { H. } 2005 . .^{31}\end{array}$ \\
\hline Patient details & Is the patient on a disability grant? & $\mathrm{Y} / \mathrm{N}$ & \\
\hline $\begin{array}{l}\text { Other medications and } \\
\text { interactions }\end{array}$ & $\begin{array}{l}\text { Has the clinician mentioned and taken note of other } \\
\text { medication the patient is on and possible interactions? }\end{array}$ & $\begin{array}{c}\mathrm{Y} / \mathrm{N} \\
\text { Document data }\end{array}$ & \\
\hline $\begin{array}{l}\text { Pregabalin dose, interval and } \\
\text { duration }\end{array}$ & $\begin{array}{l}\text { Has the dosage, interval and duration for which } \\
\text { pregabalin must be used been documented? }\end{array}$ & $\begin{array}{c}\mathrm{Y} / \mathrm{N} \\
\text { Document data }\end{array}$ & \\
\hline Follow-up plan: & $\begin{array}{l}\text { 1. Has the clinician set a date for reassessment? During } \\
\text { reassessment was the pain reassessed in terms of } \\
\text { improved function and severity? } \\
\text { 2. Did the clinician plan or refer for } \\
\text { non-pharmacological treatment? }\end{array}$ & $\begin{array}{l}\mathrm{Y} / \mathrm{N} \\
\text { Document data - } \\
\text { treatment goals and } \\
\text { referral plan }\end{array}$ & \\
\hline Patient education & $\begin{array}{l}\text { Did the clinician mention a discussion with the patient } \\
\text { in terms of possible side effects of the medication and } \\
\text { goals of treatment? }\end{array}$ & $\mathrm{Y} / \mathrm{N}$ & \\
\hline
\end{tabular}

